\title{
Can We Protect Our Patients and Employees from Childhood Diseases?
}

Nosocomial infections acquired by hospital personnel pose a special problem for the infection control practitioner. Even in an institution with an established employee health program and clearly designed procedures, an outbreak of measles or varicella causes time-consuming and expensive investigations. Chou et $\mathrm{al}^{1}$ were prompted by a measles outbreak in their community to review the available data on susceptibility of young adults to the measles virus. In their well-designed study, they investigated the measles susceptibility of 266 health care workers, especially physicians and nurses, in a metropolitan hospital; they found only one serosusceptible person. The very high prevalence of measles antibodies is surprising and can probably be attributed to the number and sensitivity of the laboratory test methods used, especially the enzyme-immunoassay and the plaque neutralization test. In another contribution in this issue, Krasinski et $\mathrm{al}^{2}$ present their experience with nosocomial varicella-zoster virus infections and the problems of effective infection control including serologic testing. Our institution recently experienced a similar infection control exercise and, like our colleagues in New York, we spent much time and money to assess the immune status of our co-workers at highest risk.

As a clinical microbiologist, 1 have been concerned about the low sensitivity of the traditional serologic tests, including those available in public health and reference centers, for

\footnotetext{
From the University of Virginia School of Medicine, Charlottesville, Virginia. Address reprint requests to Dieter H.M. Gröschel, MD, Professor of Pathology and Internal Medicine, Box 168, University of Virginia Medical Center, Charlottesville, VA 22908.
}

assessing the immune status of employees to childhood diseases. Much money has been spent, probably unnecessarily, to protect supposedly serosusceptible persons with active and passive immunizations. The more sensitive serologic tests were often available only from research laboratories, and their use in an outbreak investigation caused major logistic and fiscal difficulties to a laboratory director. Fortunately, reliable, highly sensitive test kits for the determination of antibodies to childhood diseases are finally available on the market, and this should increase the usefulness and decrease the expense of in-house testing of employees.

While the problems of possibly unnecessary immunization soon may be overcome, we are facing another dilemma, the future availability of childhood vaccines. During the past years, several manufacturers have discontinued the production of vaccines, and the remaining licensed manufacturers either suspended production or are awaiting to resolve problems with liability insurance coverage. Could it be that in the future commercial vaccines will no longer be available in the United States? We remember the recent shortage of diphtheria-pertussis-tetanus vaccine and our concerns about interrupting childhood immunization programs. At this very time, the Administration presents a budget request for the Centers for Disease Control's Immunization Program of $\$ 56$ million which is $\$ 3.6$ million less than the 1986 appropriation and $\$ 883,000$ less than the 1986 budget available after sequestering. ${ }^{3}$ Since 1963 , CDC has provided project grant support to assist state and local health agencies in planning, developing, and conducting child immunization programs. In addition, CDC has begun to stockpile childhood vaccines to serve as an emergency supply (at present for 16 weeks) for immunization campaigns. For various rea- 
sons, but mainly because of reduction of federal spending, the Administration has decided not to include funds for the expansion of the vaccine stockpile in 1987.

Since we are interested in keeping the high immunization rates of our children to prevent both community and hospital-associated outbreaks of preventable diseases, we must ask our federal legislators to vote for an increased budget for those federal agencies involved in the development of vaccines and in the administration of childhood immunization programs. Herd immunity is useful to protect the com- munity, but it does not protect the susceptibles in a special situation such as in the hospital environment.

\section{REFERENCES}

1. Chou T, Weil D, Arnow PM: Prevalence of measles antibodies in hospital personnel Infect Control 1986; 7:309-311.

2. Krasinski K, Holzman RS, La Couture $\mathbf{R}$, et al: Hospital experience with varicella-zoster virus. Infect Control 1986; 7:312-316.

3. Centers for Disease Control: Fiscal Year 1987, Volume I1, Justification of appropriation estimates for Committee on Appropriation, Dept. Health and Human Services, USPHS, 1986, pp 31-34. 